\section{Questión}

Periodismo / Comunicación ISSN 1669-6581
- Av. $44 \mathrm{~N}^{\circ} 676,1^{\circ}$ piso

CP 1900 - La Plata - Argentina

* www.perio.unlp.edu.ar/question

En este tiempo de contagios

Prof. Oscar E. Bosetti

DOI: https://doi.org/10.24215/16696581e277

\title{
En este tiempo de contagios
}

\section{In this time of contagion}

Oscar Bosetti / oscarbosetti@hotmail.com https://orcid.org/0000-0002-5593-6901

Docente en las Carreras de Grado de Comunicación Social de las Universidades Nacionales de Buenos Aires, Entre Ríos y Quilmes. Se desempeñó como Subsecretario de Medios de Comunicación de la Universidad de Buenos Aires (2002-06) y fundó UBA: FM 90.5, La Radio de la Universidad de Buenos Aires y la Agencia Radiofónica de Comunicación de la Universidad Nacional de Entre Ríos. Investigador de la Historia de la Radio Argentina. Entre otros títulos publicó: Radiofonías. Palabras y Sonidos de Largo Alcance (1994), Las tres frecuencias didácticas del dial radiofónico (1997), Las charlas radiofónicas de Discepolín: Un caso de periodismo radiofónico cultural (1999), La Radio en Argentina (2007), Noventa años de palabras y sonidos de largo alcance (2009) y Radio Nacional: Las maneras de hablar de un medio público (2010). Compilador y coautor de los libros Radios universitarias argentinas (2015) y Encrucijadas del Nuevo Milenio. Radio, Comunicación y Nuevas Tecnologías (2016) y Pensar las Radios. Reflexiones desde las cátedras, talleres y otros alrededores (2018) Miembro del Comité Ejecutivo Permanente de las Jornadas Universitarias "La Radio del Nuevo Siglo".

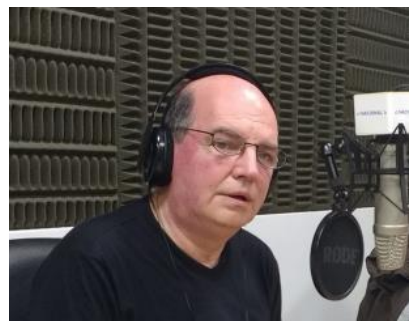

Estos raros, extraños tiempos de pandemia han instalado diferentes carpetas en el desbordado escenario que muestran los escritorios de nuestras computadoras personales. En algunas de ellas se agrupan temáticas propias de la economía capitalista neoliberal y sus inevitables resquebraduras que nunca terminan de terminar. En otras, hay suficiente material nutritivo para 
el afán investigativo de cientistas políticos y sociales, psicólogas y psicólogos, pedagogas y pedagogos, filósofas y filósofos y profesionales de la salud, entre otras y otros imprescindibles en estas horas de creciente trabajo a destajo.

En ciertas otras carpetas se reunieron las piezas indispensables para que las y los comunicadores replanteen sus certezas acerca del funcionamiento del ecosistema de los medios y las redes sociales en estos tiempos digitales. En fin, en cada una de esas carpetas se fueron alineando algunos de esos emergentes que construyó un contexto que, de un día para el otro, cambió su fisonomía y hoy no queda claro qué formas asumirá el día del después. El horizonte del futuro mediato o, peor aún, del "por venir" inmediato se han aureoleado con una espesa neblina. Habrá que atravesarla a paso lento, sin pausas y apelando a la prudencia, en sentido filosófico.

De entre todas esas carpetas que se disponen ante mi mirada elijo una compuesta por Palabras, heterogéneas Palabras que pasaron a habitar nuestros diálogos ciudadanos mediados por algún dispositivo, por alguna plataforma conocida o por conocer de manera forzada. Algunas Palabras son nuevas en el repertorio de nuestras prácticas comunicativas. Otras son tan recientes tanto para el habla como para la lengua que todavía el diccionario de la Real Academia Española no le brindó un renglón en el catálogo de sus avales.

Dentro de la carpeta elegida se rozan teletrabajo, Zoom, infodemia, Meet Google, coronavirus, Classroom, pandemia, Adobe Connect, cuarentena, protocolos, confinamiento, desinfección, barbijos, aislamiento, Jitsi, recuperadas y recuperados, tapacaras y, agazapada entre otros términos de uso confuso, leo contagio y, sin más, lo asocio con el verbo contagiar. En su edición de 1991, el Pequeño Larousse Ilustrado que apenas cuenta con 1.663 páginas, 5.000 ilustraciones, 100 mapas y 111.527 términos, le asigna al vocablo contagiar tres acepciones. Una hace referencia al acto de transmitir una enfermedad. La segunda se detiene en el otro extremo del circuito: habla de la adquisición de una enfermedad transmisible. El tercer significado se dirige a otros barrios de la vida cotidiana; expresa que también vale cuando designa eso nada inocuo que implica "transmitir una sensación".

Una vez más el apasionante, intrincado mundo de las Palabras nos invita a recorrerlo para desentrañar sus connotaciones y denotaciones, sus espesuras y tramas, sus certezas y ambigüedades. 
No tengo dudas: Hay contagios que hacen daño, debilitan, enferman, dejan secuelas negativas y hasta pueden conducir a la impar muerte. Hay contagios para el cuerpo humano. Si alguien anda con el coronavirus, el contagio pareciera que es inminente, y si no entra en cuarentena no solo su vida peligra, sino también entra en riesgo la vida de las personas con las que tiene contacto cercano.

El contagio también ocurre en eso que algunos denominan "cuerpo social". Si un padre ejerce ominosa violencia en contra de su compañera, es previsible que contagie negativamente a sus hijos, y ellos crezcan contagiados por el virus de la violencia en contra de sus amigas, novias y esposas. De igual manera, si una institución pública o una empresa privada están conducidas por empleados o funcionarios corruptos, es altamente previsible que el contagio se esparza por esos espacios, y que, como el virus, se contagie a muchos otros y otras.

Si se amanece un día con desánimo, es frecuente o inevitable que se contagie al círculo más cercano y, por el contrario, si en medio de tormentas abrumadoras e incertidumbres que no cesan, prevalece el optimismo y el buen ánimo, sin duda ambas se contagiarán en muchas otras personas. Aunque, también es cierto -no olvidemos- que no siempre los preceptos conductistas operan según la simple, mecánica e inmediata cadena de resultados como sus demiurgos pretendían lograr.

Creo que es momento de decirlo. En estos días de cuarentenas que dejaron de precisar por cuántos días están compuestas, hemos de animarnos con contagios estimulantes. Ya demasiado es la angustia de un posible contagio con el coronavirus, como para que también nos contagiemos de miedo, desesperanzas, zozobras, y todavía peor, desazón y nihilismo ante la posibilidad de aspirar a un Mundo Mejor.

Si el coronavirus se contagia con tanta rapidez y facilidad, ¿por qué no promover contagios positivos, que estimulen compromisos y actitudes proactivas para hacer frente a los enormes desafíos actuales? Necesitamos aprender del contagio del coronavirus, raudo y veloz, solo que en sentido opuesto, un contagio estimulante, afirmativo, generador de conciencia de dignidad y que contribuya a recuperar las fuerzas de cada una de nuestras comunidades que hoy viven puertas para adentro.

En los últimos tiempos hemos experimentado contagios positivos. En 2015 muchas y muchos caribeños y centroamericanos se contagiaron de las movilizaciones guatemaltecas en contra de la corrupción, y cuando supieron del saqueo del Seguro Social se indignaron y salieron a la 
calle con antorchas en sus manos. Este contagio se extendió por toda Honduras, por ejemplo, esa pequeña nación latinoamericana que sufrió el primer golpe cívico militar del Siglo XXI.

Otras comunidades defensoras de sus ríos, sus aguas, su minería y sus territorios, iniciaron la lucha por declarar a sus municipios, libres de explotación minera, libres de fracking. Esta acción contagió a otras, y luego a muchas otras comunidades. Este contagio ha logrado que cientos de comunas latinoamericanas se hayan declarado libres de minería, y algunos se declararon municipios verdes. También podríamos sumar reacciones en cadena frente a las impúdicas fumigaciones con glifosato. O la marea que agitó el Movimiento de los Pañuelos Verdes como nave insignia de la Resistencia de las Mujeres, en apoyo a la salud y los derechos sexuales y reproductivos.

Más cerca en el tiempo, en 2019, se desplegaron numerosas manifestaciones sociales en diversos rincones del planeta, unidas por un hilo conductor. Motivadas por el alza de los combustibles, el transporte o los impuestos, estallaron protestas contra las élites gubernamentales tanto en Chile como en El Líbano. En nuestro país hubo movilizaciones de las organizaciones sociales ante la indetenible depreciación de la moneda y el crecimiento del hambre y los índices de pobreza. En Bolivia tras la "cuestionada" victoria electoral de Evo Morales se radicalizaron las movilizaciones y la violencia que culminó con el Golpe de Estado que derrocara al primer mandatario, lo que generó una onda expansiva antigolpista. En tanto, en diferentes ciudades de España las marchas en solidaridad con los líderes del 1-O en prisión y en contra de la sentencia condenatoria a los principales líderes independentistas del "procés". o los chalecos amarillos en París, las y los desclasados de Haití -el país más pobre de América Latina-, las "sardinas" italianas enfrentándose en Roma contra la ultraderecha de Matteo Salvini o miles de británicas y británicos oponiéndose al cierre del Parlamento; las calles de este incompleto caleidoscopio de ejemplos fueron el escenario de las diversas fuerzas contagiadas, algunas más próximas a los idearios del progresismo otras cruzadas por las lógicas nacionales que no siempre descifran fácilmente las miradas extranjeras a esos territorios.

Muchos de esos contagios nos enriquecen, nos fortalecen, nos hermanan. Nos capacitan para hacernos fuertes en la lucha por una nueva institucionalidad democrática. Son contagios que nos dan energías positivas para convencernos que las y los corruptos y concentradores de riquezas comunes, no son invencibles; que por fuertes que parezcan, nunca tendrán las 
riquezas que son propias de los pueblos contagiados: la ética, la dignidad y la no violencia activa.

Pareciera que, frente a ese otro contagio que paraliza, aísla, pone en situación de sospecha la noción que ese universo de utopías pueda concretarse en un tiempo cercano, vale la pena no perder el rumbo y recordar que este rápido muestrario de acciones no ocurrió mucho tiempo atrás. Apenas unas semanas antes que la pandemia se desatara.

Por eso, no estaría nada mal, que cuando todo esto pase y queden las huellas de un tiempo que no imaginábamos atravesar, sigamos contagiándonos de energías positivas, manteniendo activadas las palancas que nos permita seguir sintiendo que vale la pena una vida con Independencia Nacional, Memoria, Verdad y Justicia Social. 